\title{
The Effect of School Climate on Pre-Service Physical Education Teachers' Burnout Syndrome: The Mediator and Regulatory Role of Class Level
}

\author{
Cüneyt Taşkın ${ }^{1} \&$ Tolga Kaan Bahadır ${ }^{2}$ \\ ${ }^{1}$ Kırkpınar Faculty of Sport Sciences, Trakya University, Turkey \\ ${ }^{2}$ Faculty of Sport Sciences, Kocaeli University, Turkey \\ Correspondence: Cüneyt Taşkın, Kırkpınar Faculty of Sport Sciences, Trakya University, Balkan Campus, Edirne, \\ Turkey. E-mail: cuneyttaskin@trakya.edu.tr
}

\author{
Received: January 10, 2021 Accepted: February 10, 2021 Online Published: February 16, 2021 \\ doi:10.5539/jel.v10n2p53 URL: https://doi.org/10.5539/jel.v10n2p53
}

\begin{abstract}
The main purpose of this study is to examine the mediating and regulatory role of current classroom levels in the relationship between the school climate as perceived by prospective physical education and sports course teachers and their feelings of burnout. The participants in this study included 303 teaching students, 144 women, and $159 \mathrm{men}$. The school climate scale and the school burnout scale were used to collect data. Hypotheses were tested using correlation and regression-based path analysis. The results showed that there is a negative significant relationship between perceived school climate at 1st, 2nd and 4th grade levels and school burnout, and a positive significant relationship between perceived school climate at the 3rd grade level and school burnout. In the relationship between the perceived school climate and feelings of burnout, class level has a mediating and regulatory effect. In addition, it has been determined that higher class level strengthens the feeling of burnout, while a low level weakens this feeling. By comparing the obtained results with the findings in the literature, suggestions were made to sports education researchers.
\end{abstract}

Keywords: burnout, school climate, mediator and regulatory variable, process macro

\section{Introduction}

Examining the literature shows that environmental factors affect underlying burnout perceptions for many reasons. The result of the negative interaction of individuals with their environment increases the effect of this perception even more. The concept of school climate, which constitutes the universe of educational life, has an important effect on the perception of burnout (Welsh, 2000). Namely, school climate is a social coexistence where students and teachers spend time together, share their feelings and thoughts, and interact with each other directly and indirectly. Many studies conducted in our country in recent years have examined the relationship between burnout and school climate but have failed to examine the formation process of this relationship, its agents and regulators, or the the mechanisms of the relationship (Göksal, 2018). Therefore, this study aimed to examine the mediator and regulatory role of pre-service teachers' classroom levels in the relationship between perceived school climate and their feelings of burnout.

Hoy, Tarter and Kottkamp (1991) stated that analyzing the school climate should be accurately completed in order to correctly describe and analyze schools. Kavgac1 (2010) showed that the understanding the behavioral patterns common in the school depends on the examination of the school climate. Likewise, Thomasson (2006) examined organizational behavior and saw the school climate as an important tool for better understanding of the organization. In other words, the school climate should be examined in detail in order to better observe and analyze the behavior patterns of the schools and to carry out the education and training process in a healthier and more active way. Again, teachers are an integral part of the school climate, and can be the most affected by the school climate. Over time, school climate can cause unwillingness, boredom, dissatisfaction, pressure, and stress for students who are faced with unwanted situations at school. The pressure on individuals causes psychological and physiological consequences such as tension, fatigue, and unwillingness. Under stress, individuals who are physiologically and psychologically stressed have negative attitudes and behaviors towards their jobs over time (Hoyos \& Kallus, 2005; Maslach et al., 2001). When negative attitudes and behaviors are examined, it is seen 
that people are faced with a perception of low burnout resulting in emotional exhaustion as a result of the feeling of failure, energy loss, loss of power, and unmet demands (Seferoğlu, Yıldız, \& Yücel, 2014; Deliorman et al., 2014).

The concept of burnout perception was created Freudenberger (1974), who explained the situation caused by hard work as "the state of exhaustion in the internal resources of the individual as a result of failure, wear, loss of power and energy as a result of overload or unfulfilled requests" and became widespread (Ar1 \& Honey, 2008). The most widely accepted and general definition of the concept of burnout on which studies are conducted today was made by Maslach et al. (Maslach \& Zimbardo, 1982; Maslach \& Jackson, 1981; Pines \& Maslach, 1980). According to this definition, burnout is expressed as "emotional exhaustion, depersonalization, and low personal accomplishment that often occurs in individuals who interact intensely with people for their job". In other words, burnout is a perception that occurs in individuals who are in constant interaction with people due to their job and who have to work face to face with people too much (Aksu \& Baysal, 2005).

From this point of view, it is of great importance that physical education and sports lesson teachers start their profession prepared for these negative situations, and prospective teachers should be informed about these issues during their university years. It is thought that teacher candidates, who were previously trained according to these conditions, can reveal a psychologically stronger character that can transform their climate they are in, starting in their first years as teachers. This study aims to collect data which will facilitate future studies on avoiding negative situations, such as the perception of burnout, while creating a positive school climate.

\section{Method}

In this study, the effect of school climate on the perception of burnout was examined to determine whether grade level had a mediating and regulatory effect. Below are the model shapes created for the intermediary and regulatory effects (Figures 1 and 2). The mediator and regulatory effects were examined by performing a regression-based path analysis as proposed by Hayes and Matthes (2009). Mediation and regulatory analyses were performed using Model 1 and Model 4 in the "PROCESS" macro of the SPSS program. Approval for the study was obtained from the appropriate university ethics committee (blinded for review).

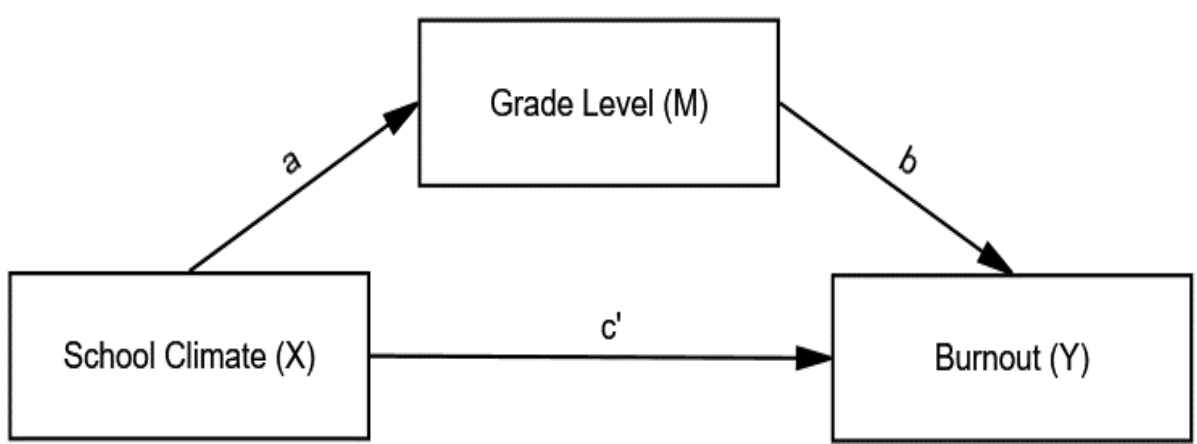

Figure 1. Mediation model to be tested

Note. Named as X (school climate), M (grade level), and Y (burnout). 

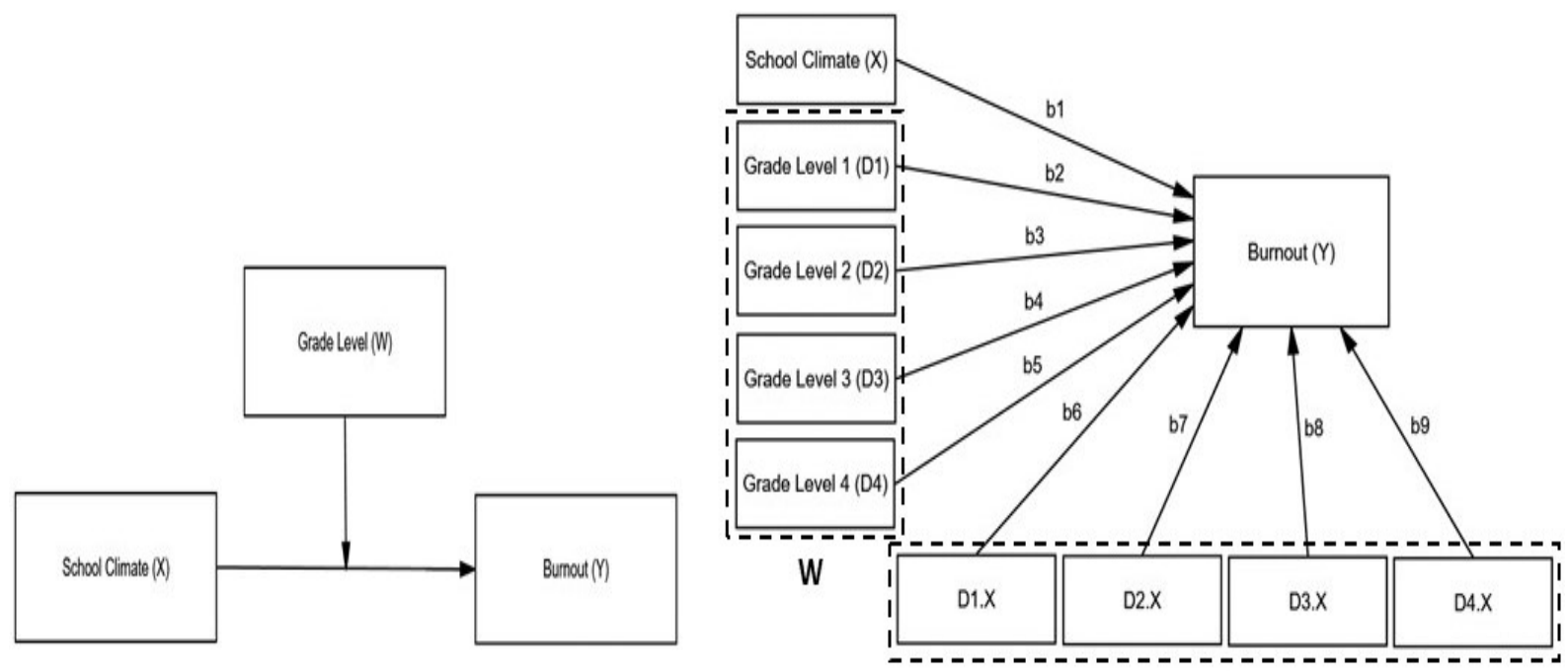

X.W

Figure 2. The theoretical and statistical representation of the regulatory effect model to be tested

Note. Named as X (school climate), W (grade level), and Y (burnout).

\subsection{Analysis}

Mediation Effect: Total effect as $\mathrm{c}=\mathrm{c} 1+(\mathrm{a} \cdot \mathrm{b})$, indirect (intermediary) effect $=\mathrm{a} \cdot \mathrm{b}$, direct effect $=\mathrm{c} 1$;

The effect of $\mathrm{X}$ on $\mathrm{Y}$ (Total effect, c); the effect of $\mathrm{X}$ on $\mathrm{M}$ (path a); while the effect of $\mathrm{X}$ (c1 path) is kept under control, the effect of $\mathrm{M}$ on the variable $\mathrm{Y}$ (path b) is significant, and if not, an indirect effect may occur (Hayes, 2018; Fritz \& MacKinnon, 2007; MacKinnon et al., 2002; Preacher \& Hayes, 2004). This is because according to advocates for the modern approach advocates, the agent impact model should be tested with the bootstrap technique instead of the Sobel test. To be able to discuss the mediating effect, the results of the bootstrap test of the indirect effect should be meaningful ( $95 \%$ confidence interval CIs should not contain 0 (zero) value). In the bootstrap/resampling technique, randomly new observations from the sample in the original data set. Samples (sub-samples) were created (Efron, 1987). In the bootstrap sampling technique, at least 2000, preferably 5000, resampling is considered sufficient for reliable predictions (DiCiccio \& Efron, 1996; Hayes, 2018; Gürbüz, 2019).

\section{Hypothesis of Mediation Effect Model}

$H_{l}$ : Grade level mediates the relationship between school climate and feelings of burnout.

Regulatory Impact: Calculated as $\mathrm{Y}=\mathrm{b}_{0}+\mathrm{b}_{1} \mathrm{X}+\mathrm{b}_{2} \mathrm{~W}+\mathrm{b}_{3} \mathrm{X} . \mathrm{W}$

After the values of the $\mathrm{X}$ and $\mathrm{W}$ variables were standardized ( $\mathrm{z}$ score), the interactional effect variable was created by multiplying the $\mathrm{X}$ and $\mathrm{W}$ variables. As a result, by looking at the effect of the interactional effect variable on the outcome variable (if it is significant), the slope analysis (Slope test) is graphically shown (Figure $3)$. 


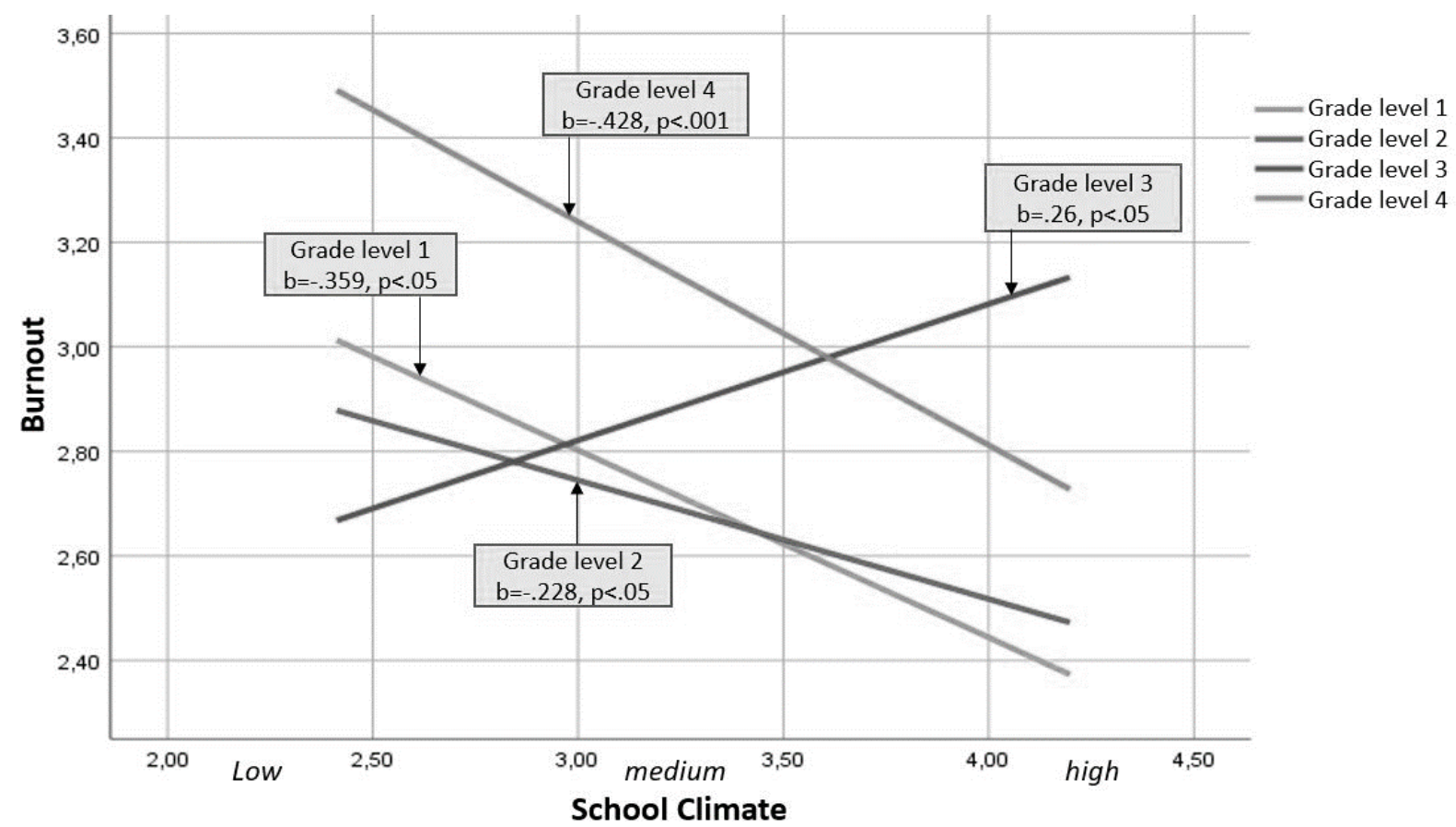

Figure 3. Slope graph of the regulatory effect of grade level variable

Hypothesis of the regulatory influence model;

$\mathrm{H}_{2}$ : School climate has a regulatory role for the grade level on burnout perception. Namely, the effect of school climate on the perception of burnout will be higher as the grade level increases, and lower as the grade level decreases.

\subsection{Participant and Sampling Procedures}

The research was carried out using a descriptive survey model. The study was composed of 1290 undergraduate students studying at Trakya University Kırkpınar Faculty of Sport Sciences. For sample selection, a 95\% confidence interval $(\alpha=0.05)$ was taken as the margin of error. According to Yazıcıoğlu and Erdoğan (2004), at a sampling error of \pm 0.05 , at least 218 elements are considered sufficient to represent a universe of 1290 elements. For the sample group, 303 students were randomly chosen. Written consent was obtained from all participants before participating in the study, and the study was conducted in accordance with the Declaration of Helsinki.

Data belonging to the school climate variable were collected using the "School Climate Scale for University Students," developed by Terzi (2015). The answers given to the 5-point Likert-type items of the measuring tool consist of 17 items, coded as 1-Never, 2-Rarely, 3-Sometimes, 4-Mostly, and 5-Always. The Cronbach's alpha reliability coefficient for the scale $=.90$. The value obtained in our study was found to be highly reliable (a $=.81$ ).

According to the confirmatory factor analysis results, we ensured the structural validity and cultural adaptation of the scale; $\mathrm{X}^{2}$ the SD ratio was determined to be 2.79, RMSEA .042, NFI .093, CFI .094, GFI .096. This showed that getting high scores on the scale reflects a positive school climate, and low scores reflect a negative school climate.

Data regarding the burnout perception variable were collected with the "School Burnout Scale" tool developed by Salmela-Aro, Kiuru, Leskinen and Nurmi (2009) and was adapted into Turkish by Seçer, Halmatov, Veyis and Ateş (2013). The answers given to the items of the 9-item scale are coded in 5-Likert type as 1-I do not agree at all, 2-I do not agree, 3-I partially agree, 4-I agree, and 5-I completely agree. The Cronbach alpha reliability coefficient for the overall scale was $\mathrm{a}=.80$. For our study, Cronbach's alpha $=.72$, which was found to be a reliable value. According to the confirmatory factor analysis results, we ensured structural validity and cultural harmony; model fit values were calculated as $\mathrm{X}^{2} / \mathrm{SD}$ ratio 3.26, RMSEA .072, NFI .090, CFI .096, GFI .092 . 
High scores from the scale refer to the perception of burnout negatively, while low scores refer to a positive reference. Based on these data, it was concluded that both scales fit well and served their purpose. The grade level variable, which is commonly used in both scales, was included in the study as a regulatory and mediator variable. Classes belonging to the department of physical education and sports teaching were coded as 1st, 2nd, $3 \mathrm{rd}$, and 4 th grades, and data were collected.

\section{Results}

In order to test whether school climate has a mediating role in burnout perception and grade level, regression analysis based on the bootstrap method was conducted. It is suggested that the bootstrap method provides more reliable results than the traditional methods of Baron and Kenny (1986) and the Sobel test (Gürbüz, 2019; Hayes 2018; Preacher, Rucker, \& Hayes, 2007; Zhao, Lynch, \& Chen, 2010). It is made using the process macro developed by Hayes (2018). In the analyses, 5000 resampling options were preferred with the bootstrap technique. In the mediation effect analysis performed with the bootstrap technique, the values obtained at the $95 \%$ confidence interval (CI) as a result of the analysis should not include the zero (0) value in order to support the research hypothesis (MacKinnon, Lockwood, \& Williams, 2004). The regression analysis results for this purpose are given in Table 1.

Table 1. The mediator role of grade level in the relationship between school climate and burnout perception

\begin{tabular}{|c|c|c|c|c|c|c|}
\hline \multirow[b]{3}{*}{ Prediction Variables } & & \multicolumn{5}{|c|}{ Outcome Variables } \\
\hline & & \multicolumn{3}{|c|}{ M (Grade level) } & \multicolumn{2}{|c|}{ Y (Perception of burnout) } \\
\hline & & $b$ & $S E$ & & $b$ & $S E$ \\
\hline X (School climate) & $a$ & $-.438 *$ & .079 & $c^{\prime}$ & $-.2503 *$ & .067 \\
\hline M (Grade level) & - & - & - & $b$ & $.182 *$ & .047 \\
\hline \multirow[t]{3}{*}{ Constant } & $i_{M}$ & $3.81^{*}$ & .267 & $\dot{I}_{Y}$ & $3.2363 *$ & .279 \\
\hline & & \multicolumn{3}{|c|}{$R^{2}=.093$} & \multicolumn{2}{|c|}{$R^{2}=.123$} \\
\hline & & \multicolumn{3}{|c|}{$\mathrm{F}(1 ; 301)=30.7809 ; p<.001$} & \multicolumn{2}{|c|}{$\mathrm{F}(2 ; 300)=21.0735 ; p<.001$} \\
\hline
\end{tabular}

Note. ${ }^{*} \mathrm{p}<.001 ;$ SE: Standard error. Non-standardized beta coefficients $(b)$ are reported.

Whether the school climate has an indirect effect on burnout perceptions was determined according to the confidence intervals obtained with the bootstrap technique. Accordingly, it was determined that the indirect effect of school climate on the perception of burnout was significant, and thus grade level mediated the relationship between school climate and burnout perception $(b=.182,95 \%$ CI $[.0908, .02741])$. Bootstrap lower and upper confidence interval values obtained by the percentage method do not include 0 (zero) values (see Figure 4 ). In light of these results, $H_{l}$ hypothesis was accepted.

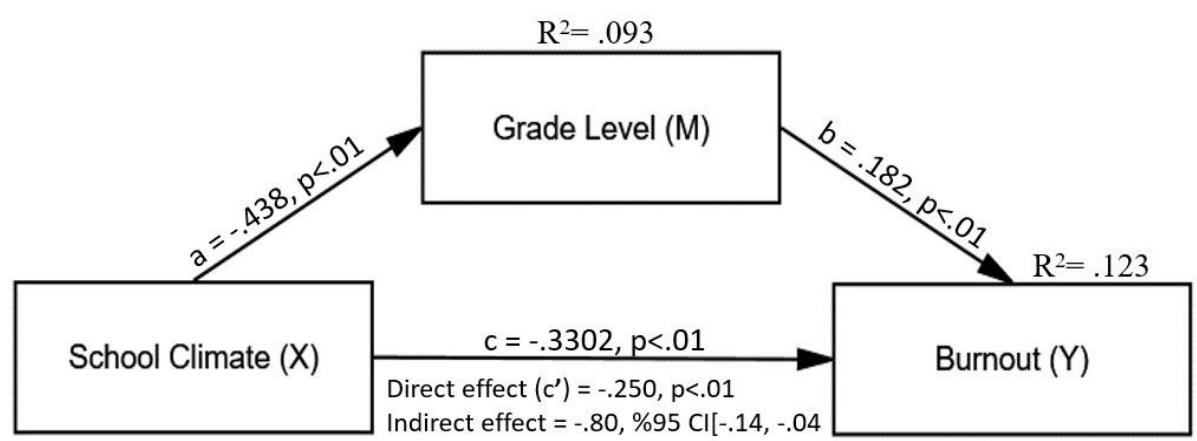

Figure 4. The mediator role of grade level in the school climate-burnout relationship $(\mathrm{N}=303)$

Regression analysis was performed using Process Macro developed by Hayes (2018) to test the regulatory role of grade level in the effect of students' perceptions of school climate on their feelings of burnout. Regression analysis results are given in Table 2. According to the results in Table 2, it was seen that all the predictive variables included in the regression analysis explained approximately $16 \%\left(\mathrm{R}^{2}=.161\right)$ of the change in feelings of burnout. It was determined that the school climate had a negative $(b=-.36, p<.001)$, and grade level had a positive $(b=.42$, $\mathrm{p}<.001$ ) and significant effect on feelings of burnout. The interactional effect (regulatory effect) of school climate 
and grade level variables on feelings of burnout was found to be significant $(b=.619, p<.05)$.

Table 2. Grade level regulatory role in the relationship between school climate and burnout perception

\begin{tabular}{llll}
\hline Variables & $b$ & SE & $t$ \\
\hline Constant & $2.70^{*}$ & .102 & 26.65 \\
& {$[2.5,2.9]$} & & \\
School climate $(X)$ & $-.36^{* *}$ & .124 & -2.89 \\
& {$[-.60,-.114]$} & & \\
Grade level $(W)$ & $.42^{* *}$ & .145 & 2.80 \\
& {$[.12, .71]$} & & \\
$X . W$ & $.62^{* *}$ & .215 & 2.89 \\
& {$[.20,1.04]$} & & \\
\hline
\end{tabular}

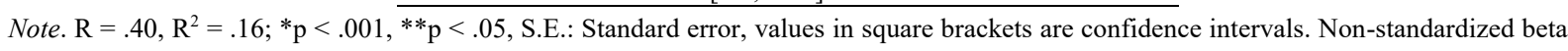
coefficients $(b)$ are reported.

As a result of the slope analysis, the effects of the regulatory variables are graphically shown in Figure 4 . When the details of the regulatory effect are examined, where the grade level is determined as 1 st Grade $(b=-.359, p<.05)$, 2nd Grade $(b=-.228, p<.05)$ and 4th Grade $(b=-.428, p<.001)$, the effect of school climate on burnout increased further in a negative way. This relationship is stronger when as the grade level increases. On the other hand, it was determined that the effect of school climate on feelings of burnout was positive $(b=.26, p<.05)$ when the grade level was 3rd grade.

\section{Discussion}

While determining the effect of school climate on the perception of burnout, the data obtained from the students in the physical education and sports teaching departments were analyzed to examine the mediating and regulatory role of grade level. It was seen that school climate had a direct significant $(p<.001)$ effect on feelings of burnout. Hypothesis $\left(H_{l}\right)$ was accepted by determining that the grade level mediates the relationship between school climate and feelings of burnout. According to this, it was concluded that the teacher candidates experienced a feeling of burnout while being affected by the negative school climate. Their feelings increase or decreased depending on the grade level, and that their classes organized by contributing to this relationship. In literature on burnout, studies indicate a significant difference according to gender and grade variables (Girgin \& Baysal, 2005; Amasral1, 2016). Studies conducted between school climate and burnout generally examined the concept of school climate through the phenomenon of administrators.

There is no research based on the perceptual difference between the first and last years of school (grade level). A lot of research in general; He reached the conclusion that "adverse school climates increase the level of burnout" (Köksal, 2018). This result is similar to our study.

Hypothesis $\left(H_{2}\right)$ stated that school climate has a regulatory role in burnout perception. Although the effect of school climate on the perception of burnout increases as the grade level increases and is lower for lower grade levels, the grade level has a negative regulatory effect between the two variables $(b=.42, p<.001)$. According to this effect, as the grade level increases, the feelings of burnout of the students increase and decrease as the grade level decreases. On the other hand, the higher the grade level, the lower the school climate perception, and the lower the grade, the higher the school climate perception. Generally, if the grade level is high, the effect of the school climate on the feelings of burnout is greater, which means that the relationship between the school climate and the feelings of burnout are regulated by the grade level; $H_{2}$ Hypothesis has also been accepted.

If we pay attention to one last point, while the grade level has a regulatory effect on the 1st, 2nd, and 4th grades, it is seen that it has a positive effect on the 3rd grade level, unlike the other classes (Figure 4). That is to say, while the school climate increases positively in 3rd grade, the feeling of burnout also increases negatively. This unexpected result creates a problem as a source for further research. We think that new results can be obtained by comprehensively examining the features of the 3 rd grade.

\section{References}

Aksu, A., Baysal, A., \& Okulu, R. Ü. P. M. Y. (2005). Principal burnout in primary school. Educational Administration: Theory and Practice, 41, 7-24.

Amasral1, A. (2016). The relationship between secondary school and high school mathematics teachers' attitudes toward organizational cynicism and level of vocational burnout (city of Amasya for sample). 
Ondokuz Mayıs University, Samsun.

Arı, G. S., \& Bal, E. Ç. (2008). The Concept of Burnout: Its Importance for Individuals and Organizations. Journal of Management and Economics, 15(1), 131-148.

Baron, R. M., \& Kenny, D. A. (1986). The moderator-mediator variable distinction in social psychological research: Conceptual, strategic, and statistical considerations. Journal of Personality and Social Psychology, 51(6), 1173. https://doi.org/10.1037/0022-3514.51.6.1173

Deliorman, B. R., Taştan, B. İ., Yiğit, İ., \& Yıldız, S. (2009). An alternative tool for the measurement of burnout: Adaptation of the Copenhagen. Burnout inventory on Marmara University academics.

DiCiccio, T. J., \& Efron, B. (1996). Bootstrap confidence intervals. Statistical Science, 189-212. https://doi.org/10.1214/ss/1032280214

Efron, B. (1987). Better boot confidence intervals. Journal of the American Statistical Association, 82(397), 171-185. https://doi.org/10.1080/01621459.1987.10478410

Freudenberger, H. J. (1974). Staff Burnout. Journal of Social Issues, 30(1), 159-165. https://doi.org/10.1111/j.1540-4560.1974.tb00706.x

Fritz, M. S., \& MacKinnon, D. P. (2007). Required sample size to detect the mediated effect. Psychology Science, 18(3), 233-239. https://doi.org/10.1111/j.1467-9280.2007.01882.x

Girgin, G., \& Baysal, A. (2005). The level of professional burnout and some variables of teachers who teach mentally retarded students (izmir sample). Pamukkale University Journal of Education, 18(18), 1-10.

Gürbüz, S. (2019). Structural equation modeling with AMOS. Ankara: Seçkin Publishing.

Hayes, A. F. (2018). Partial, conditional, and moderated mediation: Quantification, inference, and interpretation. Communication Monographs, 85(1), 4-40. https://doi.org/10.1080/03637751.2017.1352100

Hayes, A. F., \& Matthes, J. (2009). Computational procedures for probing interactions in OLS and logistic regression: SPSS and SAS implementations. Behavior Research Methods, 41(3), 924-936. https://doi.org/10.3758/BRM.41.3.924

Hoy, W. K., Tarter, C. J., \& Kottkamp, R. B. (1991). Open schools, healthy schools: Measuring organizational climate. Corwin Press.

Hoyos, T., \& Kallus, K. W. (2005). Burnout risk factors: Stress-recovery-state and coping among teachers. Department of Psychology. University of Graz. Austria.

Kavgac1, H. (2010). Organizational climate and school-family relations in primary schools. Unpublished master's thesis. Gazi University, Ankara.

Köksal, S. (2018). The Relationship Between Perceived School Climate and Burnout Levels by Mathematics Teachers. Doctoral dissertation, Kültür University, İstanbul.

MacKinnon, D. P., Lockwood, C. M., \& Williams, J. (2004). Confidence limits for the indirect effect: Distribution of the product and resampling methods. Multivariate Behavioral Research, 39(1), 99-128. https://doi.org/10.1207/s15327906mbr3901_4

Maslach, C., \& Jackson, S. E. (1982). The measurement of experienced burnout. Journal of Organizational Behavior, 2(2), 99-113. https://doi.org/10.1002/job.4030020205

Maslach, C., Schaufeli, W. B., \& Leiter, M. P. (2001). Job burnout. Annual Review of Psychology, 52(1), 397-422. https://doi.org/10.1146/annurev.psych.52.1.397

Pines, A., \& Maslach, C. (1980). Combatting staff burn-out in a day care center: A case study. Child Care Quarterly, 9(1), 5-16. https://doi.org/10.1007/BF01555032

Preacher, K. J., \& Hayes, A. F. (2004). SPSS and SAS procedures for estimating indirect effects in simple mediation models. Behavior Research Methods, Instruments, \& Computers, 36(4), 717-731. https://doi.org/10.3758/BF03206553

Preacher, K. J., Rucker, D. D., \& Hayes, A. F. (2007). Addressing moderated mediation hypotheses: Theory, methods, and prescriptions. Multivariate Behavioral Research, 42(1), 185-227. https://doi.org/10.1080/00273170701341316

Salmela-Aro, K., Kiuru, N., Leskinen, E., \& Nurmi, J. E. (2009). School burnout inventory (SBI) reliability and validity. European Journal of Psychological Assessment, 25(1), 48-57. 
https://doi.org/10.1027/1015-5759.25.1.48

Seçer, İ., Halmatoc, S., Veyis, F., \& Bümyamin, A. T. E. S. (2013). Adapting School Burnout Inventory to Turkish Culture: Study of Validity and Reliability. Turkish Journal of Education, 2(2), 16-24.

Seferoglu, S. S., Yildiz, H., \& Yücel, Ü. A. (2014). Teachers' burnout: Indicators of burnout and investigation of the indicators in terms of different variables. Education and Science, 39(174). https://doi.org/10.15390/EB.2014.2515

Terzi, A. R., \& BAÜ, N. E. F. (2015). Developing a school climate scale for university students. Journal of Research in Education and Teaching, 4(4), 111-117.

Thomasson, V. L. (2006). A study of the relationship between school climate and student performance on the Virginia standards of learning tests in elementary schools.

Welsh, W. N. (2000). The effects of school climate on school disorder. The Annals of the American Academy of Political and Social Science, 567(1), 88-107. https://doi.org/10.1177/000271620056700107

Yazıcıŏglu, Y., \& Erdoğan, S. (2004). SPSS applied scientific research methods. Ankara: Detay Publishing.

Zhao, X., Lynch Jr, J. G., \& Chen, Q. (2010). Reconsidering Baron and Kenny: Myths and truths about mediation analysis. Journal of Consumer Research, 37(2), 197-206. https://doi.org/10.1086/651257

\section{Copyrights}

Copyright for this article is retained by the author, with first publication rights granted to the journal.

This is an open-access article distributed under the terms and conditions of the Creative Commons Attribution license (http://creativecommons.org/licenses/by/4.0/). 